\title{
Sildenafil and Female Sexual Dysfunction: Isn't It Time to Target the Right Candidates?
}

\author{
Marjan Khajehei $^{1}$, Maryanne Doherty ${ }^{2}$ \\ Sexology Department, School of Public Health, Curtin University, Bentley, Western Australia \\ ${ }^{1}$ marjan.khajehei@postgrad.curtin.edu.au; ${ }^{2}$ M.Doherty@curtin.edu.au
}

\begin{abstract}
Female sexual arousal disorder (FSAD) is one of the subcategories of female sexual dysfunction (FSD). During recent years, many different chemical and herbal medicines have been introduced to the market by pharmaceutical companies targeting women who suffer sexual dysfunction. Notwithstanding, the majority of these medications failed to demonstrate their efficacy in experimental studies. Regarding the fact that men and women are increasingly becoming similar in terms of life style, familial and social responsibilities, etc, treating female sexual problems by the use of sildenafil citrate (Viagra) has become of interest to many physicians and professionals. This drug is a phosphodiesterase type 5 inhibitor and is commonly used for the treatment of erectile dysfunction. Evaluation of the effect of sildenafil on FSAD has yielded controversial results and still there is no unanimity on this issue. The focus of this review article is on the efficacy of sildenafil as a treatment for FSAD. Regarding the fact that women's sexual dysfunction is a biopsychosocial disorder with a multifaceted etiology, it is proposed that the sole use of sildenafil may not be an effective treatment for FSAD. All aspects of female sexuality should be taken into account during evaluation of female sexual function and when therapeutic approaches for FSAD are introduced. As a matter of fact, women's sexual problems may become worse and their self-confidence may be negatively affected if improper treatment approach is nominated.
\end{abstract}

Keywords-Female Sexual Arousal Disorder; Female Sexual Dysfunction; Sildenafil

\section{INTRODUCTION}

Sexual response cycle includes four main elements, namely desire, arousal (excitement), orgasm and resolution ${ }^{\text {[1] }}$. Each domain of sexual response cycle can be deteriorated by many factors and result in sexual dysfunction, which is described as "an inability to perform or reach an orgasm, painful sexual intercourse, a strong repulsion of sexual activity, or an exaggerated sexual response cycle or sexual interest" ${ }^{2]}$. The prevalence of female sexual dysfunction (FSD) among general population has been reported to vary from $31.5 \%{ }^{[3]}, 43 \%{ }^{[4]}, 46.9 \%{ }^{[5]}$, to $91 \%{ }^{[6]}$. Female sexual arousal disorder (FSAD) is one of the most prevalent sub-categories of FSD (Table I) ${ }^{[2,7-11]}$ that has been reported to affect $10-76.1 \%$ of women of all ages ${ }^{[6,12,13]}$.

TABLE I CATEGORIES OF SEXUAL DYSFUNCTION IN WOMEN

\begin{tabular}{|c|c|}
\hline Type of Sexual Dysfunction & Description \\
\hline Sexual Interest/Desire Disorder & $\begin{array}{l}\text { Lack of or diminished sexual interest, sexual thoughts or fantasies, } \\
\text { responsive desire motivation scarce or absent. } \\
\text { Lack of interest beyond what naturally occurs with age and } \\
\text { duration of relationship. }\end{array}$ \\
\hline $\begin{array}{l}\text { Subjective Sexual Arousal } \\
\text { Disorder }\end{array}$ & $\begin{array}{l}\text { Sexual stimulation results in little to no feelings of sexual arousal; } \\
\text { however, vaginal lubrication and other physical responses occur. }\end{array}$ \\
\hline $\begin{array}{l}\text { Subjective Genital Arousal } \\
\text { Disorder }\end{array}$ & $\begin{array}{l}\text { Diminished or lack of genital sexual arousal such as vaginal } \\
\text { lubrication or vulval swelling from any type of sexual stimulation; } \\
\text { nongenital stimuli still cause subjective sexual excitement. }\end{array}$ \\
\hline $\begin{array}{l}\text { Combined Genital and } \\
\text { Subjective Arousal Disorder }\end{array}$ & $\begin{array}{l}\text { Sexual stimulation results in little to no feelings of sexual arousal } \\
\text { in addition to lack of or impaired genital arousal such as vaginal } \\
\text { lubrication. }\end{array}$ \\
\hline $\begin{array}{l}\text { Persistent Sexual Arousal } \\
\text { Disorder }\end{array}$ & $\begin{array}{l}\text { Spontaneous genital throbbing, tingling, pulsating that is } \\
\text { unrelieved by orgasm and occurs in the absence of sexual interest } \\
\text { and desire. } \\
\text { Feelings of arousal occur for hours to days. }\end{array}$ \\
\hline Women's Orgasmic Disorder & $\begin{array}{l}\text { Absence of, diminished intensity of, or delay of orgasm from } \\
\text { stimulation. }\end{array}$ \\
\hline Vaginismus & $\begin{array}{l}\text { Difficulty allowing vaginal entry of the penis, finger, or other } \\
\text { objects despite the woman's desire to do so; usually occurs with } \\
\text { involuntary pelvic muscle contractions and may be accompanied } \\
\text { by avoidance, fear, and/or anxiety. }\end{array}$ \\
\hline Dyspareunia & Recurrent pain with attempted or complete entry into the vagina. \\
\hline Sexual Aversion Disorder & $\begin{array}{l}\text { Feelings of disgust, fear, or anxiety regarding anticipation or } \\
\text { attempt at sexual activity, which usually leads to avoidance; may } \\
\text { be derived from a history of physical or sexual abuse or childhood } \\
\text { trauma. }\end{array}$ \\
\hline
\end{tabular}


Table I was reprinted from: Brown, D., Kyle, J., \& Ferrill, M. (2009). Assessing the clinical efficacy of sildenafil for the treatment of female sexual dysfunction. Annals of Pharmacotherapy, 43(7), 1275-1285; with written permission from the publisher (Greg Johnson, Advertising and Marketing Manager of The Annals of Pharmacotherapy).

Women's sexuality was strongly suppressed during the Victorian era. They were regarded to lack sexual feeling or were expected to avert their desire for sex. During this period of history, women who enjoyed sex or were sexually active were known to be unusual individuals with odd personalities. They were doomed to be hospitalized, receiving medications or psychotherapy, and in many cases undergoing female genital mutilation ${ }^{[14]}$.

Recent years, however, have been the age of revolution in the achievement of women's rights. Advocators have made appropriate movements in order to show that women should feel free to express their sexual feelings as well as men. They need to have joyful sexual activities and must have access to therapeutic options for their sexual difficulties. This resulted in the introduction of both herbal and chemical medicines by many pharmaceutical companies. Nevertheless, experimental studies have revealed that not all introduced medicines are successful in the treatment of female sexual dysfunction ${ }^{[15]}$.

Women's sexual problems has been recently targeted to be treated by the use of drugs that have primarily been used to treat male sexual dysfunction ${ }^{[16]}$. The possible reasons behind this may be the followings: i) in nowadays societies, men and women are becoming more similar in terms of various aspects of life including life style, familial and social responsibilities, etc; ii) the physiology of genital smooth muscle of male and female are almost similar at the time of exposure to sexual stimuli; iii) the prevalence of sexual problems is higher among women than men based on the reports of numerous studies from multiple countries ${ }^{[4,17,18]}$.

Sildenafil citrate (Viagra) is one of the medicines that is primarily identified as an effective treatment for male erectile dysfunction (ED). Its therapeutic effect on ED was accidentally discovered when it was prescribed to male angina patients and the majority of patients reported having strong erection after taking the medicine ${ }^{[19]}$. Due to its success in the treatment of male erectile dysfunction, scientists have been tempted to investigate the effect of sildenafil on females sexual arousal disorder since $1996^{[11]}$. Nevertheless, different studies have reported controversial findings and the use of sildenafil in the treatment of female sexual problems is still a debatable issue.

This article aims to review available literature on the application of sildenafil in the treatment of female sexual arousal disorder. The paper also endeavours to come up with a conclusion whether this medication can be considered as a miracle for women suffering arousal disorder or not.

\section{SEXUAL RESPONSE CYCLE AND MECHANISM OF AROUSAL IN MEN AND WOMEN}

Sexual response cycle consists of four main phases including desire, arousal, orgasm, and resolution. Because the main focus of this article is on the arousal phase which is expected to be affected by sildenafil, physiological changes during this phase in men and women will be discussed first.

\section{A. Male Physiological Changes during Arousal Phase}

Erection of penis, which varies from partially to fully arouse in different men, is the main characteristic of the male arousal phase. The rigidity of penis differs from time to time and mainly bases on signals sent by Central Nervous System (CNS) and peripheral stimuli. Penile rigidity is also affected by a complex interaction between neurotransmitters, vasoactive agents and endocrine agents ${ }^{[20]}$. During arousal phase, the penile trabecular smooth muscles relaxation happens under the effect of nonadrenergic-noncholinergic autonomic nerves and also the release of nitric oxide (NO) from vascular endothelium into penile corpus cavernosum ${ }^{\text {[21] }}$. The creation of cyclic guanosine monophosphate (cGMP) and in turn the commencement of smooth muscle relaxation is triggered by $\mathrm{NO}^{[22]}$. As a result, vascular resistance is diminished and blood flows through sinusoidal spaces in the paired corpora cavernosa. This process results in the compression of the subtunical venular plexus under the tunica albuginea. Consequently, there is a remarkable drop in the blood outflow followed by penile erection ${ }^{[23]}$. Other changes in the male body during this phase include the dilation of urethral bulbs and the ascent of testes in scrotum ${ }^{[24]}$.

\section{B. Female Physiological Changes during Arousal Phase}

It has been shown that a group of hormones and chemicals influence female arousal. Androgen and estrogen receptors facilitate the positive effects of androgens and estrogen, respectively, to create female sexual arousal. In addition, the conversion of intracellular testosterone into estrogen, and also cholesterol into sex hormones (neurosteroids) in brain can have substantial impacts on sexual arousal of women. The existence of NO synthase in the clitoral tissue of women may also have significant influence on female sexual arousal ${ }^{[25,26]}$. Hormonal and chemical factors stimulate the dilation of smooth muscle cells around blood spaces in genital organs and result in the increase of blood inflow. Accordingly, the engorgement of clitoris and labia minora, the eversion of labia minora, and the increase of the length and diameter of both vagina and clitoris happen that can be considered as the most noticeable changes of genital organs during female sexual arousal ${ }^{[27]}$. Furthermore, vaginal lubrication occurs as a result of ultrafiltration of plasma into vagina. This in turn prohibits painful penile-vaginal insertion, facilitates the sperm movement and increases the possibility of fertilization ${ }^{[28]}$. Vaginal enlargement (due to contraction of 
smooth muscles) and uterus and cervical ascent (due to contraction of lavator ani muscles) result in "vaginal tenting” during arousal phase ${ }^{[29]}$.

Timing and duration of the arousal phase of sexual response cycle varies between men and women ${ }^{\text {[30] }}$. It may last from less than a minute to over several hours ${ }^{[28]}$ and can be affected by factors including sexual stimulation, Central Nervous System (CNS), peripheral neurovascular pathway, hormonal alterations, and many more social, cultural and environmental factors ${ }^{\text {[31] }}$

\section{IS SILDENAFIL A REAL MIRACLE FOR WOMEN?}

The pathway of NO-cGMP (described in previous section of this paper) can be blocked by phosphodiesterase type 5 (PDE5), officially known as sildenafil citrate, and lead in prolonged erection ${ }^{[26]}$. Sildenafil citrate has been reported to improve male sexual function and has been approved by the Food and Drug Administration (FDA) on March 27, 1998 to be applied for the treatment of male erectile dysfunction ${ }^{[32,33]}$. Promotional activities for sildenafil primarily targeted "men of a certain age" suffering erectile dysfunction ${ }^{[34]}$. The promotion was, however, so vigorous that made even young healthy men to rush to drugstores in the hope of optimizing their sexual performance with sildenafil ${ }^{\text {[35] }}$.

The positive effect of sildenafil on men's erectile function inspired researchers across the world to examine the efficacy of the drug in the treatment of female sexual arousal disorder (FSAD) ${ }^{[36-38]}$. Notwithstanding, studies evaluating the effect of sildenafil on female sexual functioning have yielded controversial results and even in some cases their findings are devastating.

\section{A. Studies Supporting the Efficacy of Sildenafil in the Treatment of FSD}

In an American placebo controlled study ${ }^{[39]}, 202$ postmenopausal women with FSAD were allocated to two groups to received either sildenafil (50 mg, adjustable) or placebo. Findings of the study demonstrated that women with FSAD who did not have concomitant hypoactive sexual desire disorder (HSDD) received sildenafil showed more improvement in their sexual function than their placebo receiving counterparts $\operatorname{did}(\mathrm{p}<0.02)$. Women who suffered both HSDD and FSAD did not show significant changes in their sexual functioning after taking medications. Berman et al. declared that sildenafil can be a proper treatment for women who only have arousal disorder without hypoactive sexual desire disorder. Nevertheless, the potential causes of FSAD in the participants were not explored. Moreover, the existence of any psychological and/or neurological impairment possibly affecting women's sexual arousal was not investigated. The results of the study by Berman et al. might not be too surprising if the latter had been the case in the study by Berman et al. Indeed, research has shown that women who suffer some kinds of neurological impairment may have a desire for sex but may not experience genital arousal. This group of women have been shown to benefit from the prescription of sildenafil as reported by Alexander et al. ${ }^{[40]}$. In a randomized double blind trial in Sweden, 129 women with spinal cord injury (SCI) were recruited and assigned to either sildenafil group (study group) or placebo group (control group). With regards to the medicine's efficacy and also tolerability of the participants, different doses of sildenafil from $25 \mathrm{mg}$ to 50 and $100 \mathrm{mg}$ were prescribed. Analysis of the data revealed that both the study and control groups showed an increase in the frequency of sexual activities. However, the difference between groups was not statistically significant. Sildenafil was able to enhance the scores of sexual function and sexual quality of life with no statistically significant differences between groups. Alexander et al. asserted that although sexual function of women with SCI may be promoted by the use of sildenafil, this influence might not be too remarkable.

In a double-blind, placebo-controlled study ${ }^{[41]}$, sexual function of nineteen women, who suffered from spinal cord injury (SCI), was investigated. Participants were randomly assigned to either sildenafil-receiving group or placebo-receiving group. The vaginal congestion was measured by Vaginal Photoplethysmography method. Results of the study showed that scores for subjective arousal significantly increased in sildenafil-receiving group ( $\mathrm{P}<0.01$ between groups). The amelioration of sexual dysfunction was more striking when a combination of sildenafil and sexual stimulation in addition to visual and manual stimulation were applied. Although the increase of vaginal congestion was more remarkable in the sildenafil-receiving group, there was no statistically significant difference between groups in this regard $(\mathrm{P}=0.07)$. Sipski et al. concluded that sildenafil might create partial improvement in sexual dysfunction of women with SCI.

In a study by Salerian et al. ${ }^{[42]}$, sixty-one men and thirty-one women, who referred to an outpatient psychiatric clinic, received sildenafil to treat their psychotropic-induced sexual problems (doses ranged from 12.5 to $100 \mathrm{mg}$ ). Findings of the research demonstrated that both men and women showed significant improvement in scores of arousal, libido, orgasm and overall sexual satisfaction and there was a statistically significant difference between before and after the intervention in either study group. It seems that the increase of women's libido in the study by Salerian et al. has been a psychological response to sildenafil resulting in the improvement of women's libido. Earlier research has shown that response to a medication and improvement in situation can occur even when individuals receive placebo due to a psychological response to the drug ${ }^{\text {[43] }}$. Therefore the promotion of libido in participants in the study by Salerian et al. might have been due to them expecting a positive change in their sexual desire after using sildenafil.

The aim of a placebo-controlled Brazilian study was to investigate clitoral blood flow and sexual function of participants [44]. To this aim, twenty-two women were assigned to either sildenafil or placebo group. Results of the study revealed that 
sildenafil was more effective than placebo in the increase of clitoral blood flow. The frequency of masturbation was higher in women taking sildenafil than women taking placebo $(\mathrm{p}<0.05)$. Nonetheless, the results of study may not be generalized to a larger population due to the small number of participants in the study.

\section{B. Studies Questioning the Efficacy of Sildenafil in the Treatment of FSD}

In a multiple countries study ${ }^{[45]}, 583$ estrogenized women, 201 estrogen-deficient women, and 108 untreated healthy women were assigned to three groups. The estrogenized group received 10, 50 or $100 \mathrm{mg}$ sildenafil, the estrogen-deficient group received $50 \mathrm{mg}$ sildenafil and the healthy women received no medication (control group). It was reported that women who received sildenafil did not represent any improvement in their sexual response, and the differences between those who received sildenafil and control group were not statistically significant. A literature review article by Wylie et al. ${ }^{[15]}$ also reported that prescription of sildenafil has no positive effect on female sexual dysfunction.

In an American prospective study ${ }^{[46]}$ thirty-three pre- and postmenopausal women were recruited and were prescribed with $50 \mathrm{mg}$ sildenafil. The sexual function of participants was evaluated by the use of Index of Female Sexual Function (IFSF). Findings of the study revealed that overall sexual function was not affected by the use of sildenafil in spite of a minor increase in the amount of vaginal lubrication and the sensitivity of clitoris. Findings of a double-blind, crossover study by Van Der Made ${ }^{[47]}$ demonstrated that when testosterone or vardenafil were used alone, no effects was recorded. Nevertheless, when a combination of the medications was administered, significant changes were observed. In addition, women who primarily had high level of attention for sexual cues did not respond to the combination of the drugs. In contrast, women who primarily had low attention for sexual cues, significantly responded to the combination of testosterone and vardenafil and showed higher improvement in genital lubrication and also subjective vaginal arousal.

The philosophy behind the use of sildenafil in the improvement of quality of sexual life of women may be the assumption that men and women have identical sexual response cycle, and that the enhancement of genital vasocongestion and vaginal lubrication with the use of sildenafil may positively affect female psychological sexual arousal ${ }^{[48]}$. These assumption are mainly based on the primary model of sexual response cycle suggested by William Masters and Virginia Johnson in $1966^{[49]}$. The assumption is justified as follows: physical response to sexual stimuli is significantly associated with individual's subjective sexual arousal and her psychological inclination to initiate sexual activity. In other words, having genital response to the medication is a symptom of individual's psychological sexual arousal ${ }^{[48,50]}$. This assumption seems to be unrealistic as subjective sexual arousal in women consists of mental sexual arousal, enhanced sensitivity of genital and nongenital areas in response to sexual stimuli, having a sense of genital congestion, awareness of vaginal lubrication and other changes in the body. It is associated with informed sexual desire and pleasure ${ }^{[51,52]}$.

Men and women have been reported to differ in terms of subjective and physiological aspects of sexual response. Male's physiological genital response is usually in accordance with his subjective sexual response. While, there is sometimes disagreement between female's subjective and physiologic sexual response. Women who suffer sexual dysfunction represent lower concordance between their subjective and physiologic sexual response. This suggests that genital and subjective sexual arousal disagreement of women may be a significant indicator of their sexual dysfunction and may particularly be related to sexual arousal disorder ${ }^{[53-55]}$.

It has been shown that female genital response may be provoked by a broad spectrum of stimuli without any subjective sexual arousal. Administration of some medicines such as sildenafil may result in genital response and vaginal lubrication in laboratory, but it does not necessarily mean that subjective sexual arousal has occurred and that the individual is experiencing a sexually arousing stimulus ${ }^{[56,57]}$. Evidence to this claim is the reports by sexually assaulted women who have experienced genital response, vasocongestion and orgasm during the assault. This may justify that the vaginal vasocongestion may be initiated in the absence of a conscious feeling of sexual arousal ${ }^{[48]}$.

It has been suggested that the frequency of sexual activities in men suffering erectile dysfunction may not be greatly influenced by the use of sildenafil ${ }^{[58]}$, and that without having relationship satisfaction men may not claim that sildenafil is the messenger of sexual happiness ${ }^{[59]}$. These reports suggest that in order for sildenafil to be effective and to work properly, there is substantial need for primary sexual desire.

These explanations may help to understand why some medications such as sildenafil may not help to improve sexual arousal disorder in women, as the problem may be a result of discordance between subjective and physiologic sexual response. Studies evaluating the effects of medications on female sexual function have reported that drugs may significantly induce genital arousal, but they may not change the self-reported sexual arousal ${ }^{[60,61]}$. Sildenafil has been made to boost genital vasocongestion but not to improve the desire for sex or promote the psychological sexual arousal. Although perception of increased genital stimulation may be enhanced with the use of sildenafil ${ }^{[39,62]}$, it may, in turn, enhance the discordance and induce sexual aversion ${ }^{[46]}$, orgasmic dysfunction ${ }^{[62,63]}$ or hypersensitivity of clitoris ${ }^{[39]}$.

Other aspect of medication prescription that must be taken into consideration is the drug's side effects. It has been reported that the use of sildenafil may leave individuals with consequences that may put its application under question. Both men and women have been reported to experience side effects after using sildenafil in many clinical trials. Some of the side effects of 
sildenafil include but not limited to flushing, headache, abnormal vision, vasodilatation, dyspepsia, nasal congestion, muscle pain, sedation, and low diastolic blood pressure ${ }^{[40,45,64-66]}$. In some studies the severity of consequences has increased parallel to the increase of the dose of sildenafil. In addition, reports of a few studies have revealed that even some patients had to stop taking sildenafil due to experiencing severe side effects ${ }^{[45,67]}$.

\section{IV.COMMENTS AND CONCLUSION}

The recent breakthroughs in medical sciences and the increasing variety of medications have helped elongate people's life and promote their quality of life. Nevertheless, the growing use of chemical medicines to resolve all kinds of diseases, dysfunctions and difficulties seems to be a problem of societies in the 21 st century ${ }^{[68]}$. These days, societies are witnessing the increasing similarity between men and women regarding their responsibilities and abilities in both familial and societal levels. Nonetheless, it should not be taken for granted that men and women still possess basic biological differences. Regarding the fact that many different root causes may contribute to female sexual dysfunction, female sexual dysfunction must be distinguished from male sexual dysfunction and the treatment of sexual problems of women needs to be regarded independently and carefully ${ }^{[8]}$.

Sildenafil is a chemical substance whose mechanism of action in most men and minority of women is through controlling a physiological process. It is not the potion of intimacy and love. What sildenafil does is similar to many antidepressants which only suppress the demonstration of psychological symptoms and do not eradicate the main causes inducing psychological problems ${ }^{[34]}$. More than forty years ago, it was asserted that psychogenic etiology is responsible for $90 \%$ of cases of sexual dysfunction and only $10 \%$ of sexual dysfunction cases result from organic causes ${ }^{[69]}$. However, after the introduction of sildenafil citrate to market during last decade, new statistics interestingly report that $80 \%$ of sexual problems are rooted back in organic dysfunction, while, psychological problems are the cause of $20 \%$ of sexual difficulties ${ }^{[70,71]}$.

In spite of the isolation of PDE5 from the penis in men and smooth muscle of the clitoris ${ }^{[26]}$, its existence in the vagina is still under question and there has been no unanimity on the issue by today. Women's sexual arousal - including vaginal vasocongestion and lubrication - differs from male arousal and has different physiological process, as the main factors inducing penile erection has been known to be NO. Although some researchers believe that vaginal vasocongestion and lubrication is substantially affected by NO ${ }^{[72,73]}$, other research has reported that women carry very low levels of NO synthetase in their blood vessels than men do, and this substance is almost undetectable in menopausal women ${ }^{[74]}$. Therefore, sexual arousal of women appears not to be significantly influenced by sildenafil ${ }^{[75]}$.

Because general well-being and quality of life of women may be highly affected by any impairment in their normal sexual functioning and elements of sexual response cycle ${ }^{[61,76]}$, it is necessary to resolve sexual problems of women considering appropriate treatment approaches for either sex, male or female. Pharmaceutical companies magnify and sometime exaggerate the effect of sildenafil on the enhancement of men's self-confidence indicating that it can optimize their sexual functioning. Nevertheless, this review article suggests that self-confidence of women may decrease after using sildenafil as they may notice no positive change in their sexual functioning. Having low level of sexual desire or arousal may not be perceived as a dysfunction by some women. But, if they are told that their low level of desire, arousal, or not reaching orgasm is a dysfunction, they may become less confident. They may even become more devastated after using sildenafil and not seeing any positive changes.

Sexual dysfunction of women is not a mere physiologic event. In fact, it is influenced by many internal and external factors including psychosocial, biological, and hormonal factors. It is also noteworthy to mention that there are many various ways to promote the quality of sexual life of women other than using chemical medications. Sildenafil should be the last option and must be used only for the right cases as not all women may benefit from its use.

\section{ACKNOWLEDGMENT}

The article has been written whilst Marjan Khajehei has been a Curtin International Research Scholar in Australia.

\section{REFERENCES}

[1] Stuasmire, J., Sexuality at the end of life. American Journal of Hospitality and Palliative Care, 2004. 21: p. 33-39.

[2] American Psychiatric Association, Diagnostic and Statistical Manual of Mental Disorders-IV-TR. 2003: Washington, DC.

[3] Safarinejad, M., Female sexual dysfunction in a population-based study in Iran: prevalence and associated risk factors. Int J Impot Res, 2006. 18(4): p. 382-395.

[4] Laumann, E., A. Paik, and R. Rosen, Sexual dysfunction in the United States: prevalence and predictors. Journal of the American Medical Association, 1999. 281(6): p. 537-544.

[5] Cayan, S., et al., The prevalence of female sexual dysfunction and potential risk factors that may impair sexual function in Turkish women. Urology International, 2004. 72: p. 52-57.

[6] Nusbaum, M. and G. Gamble, The prevalence and importance of sexual concerns among female military beneficiaries. Military Medicine, 2001. 166(3): p. 208-210. 
[7] Berman, J., L. Berman, and I. Goldstein, Female sexual dysfunction: incidence, pathophysiology, evaluation, and treatment options. Urology, 1999. 54(3): p. 385-391.

[8] Basson, R., et al., Report of the international consensus development conference on female sexual dysfunction: definitions and classifications. The Journal of Urology, 2000. 163(3): p. 888-893.

[9] Segraves, R., R. Balon, and A. Clayton, Proposal for changes in diagnostic criteria for sexual dysfunctions. Journal of Sexual Medicine 2007. 4: p. 567-580.

[10] 1Basson, R., Are the complexities of women's sexual function reflected in the new consensus definitions of dysfunction? Journal of Sex and Marital Therapy, 2001. 27(2): p. 105-112.

[11] Brown, D., J. Kyle, and M. Ferrill, Assessing the clinical efficacy of sildenafil for the treatment of female sexual dysfunction Annals of Pharmacotherapy, 2009. 43(7): p. 1275-1285.

[12] Rosen, R., Prevalence and risk factors of sexual dysfunction in men and women Current Psychiatry Reports, 2000. 2(3): p. $189-195$.

[13] Shifren, J., et al., Sexual problems and distress in United States women: prevalence and correlates. Obstetrics \& Gynecology, 2008. 112(5): p. 970-978 10.1097/AOG.0b013e3181898cdb.

[14] World Health Organization, Female genital mutilation: report of a World Health Organization technical working group. 1995: Geneva.

[15] Wylie, K. and F. Malik, Review of drug treatment for female sexual dysfunction. International Journal of STD \& AIDS, 2009. 20(10): p. 671-674.

[16] 16. Bancroft, J., The medicalization of female sexual dysfunction: the need for caution. Archives of Sexual Behavior, 2002. 31(5): p. 451-455.

[17] Lindau, S., et al., A study of sexuality and health among older adults in the United States. New England Journal of Medicine, 2007. 357: p. $762-774$.

[18] West, S., et al., Prevalence of low sexual desire and hypoactive sexual desire disorder in a nationally representative sample of US women. Arch Intern Med, 2008. 168(13): p. 1441-1449.

[19] Del Mar, C., J. Doust, and P. Glasziou, Models of disease, in Clinical thinking: evidence, communication and decision-making. 2006, Blachwell Publishing: Massachusetts. p. 27-37.

[20] Creed, K., C. Carati, and E. Keogh, The physiology of penile erection. Oxford Reviews of Reproductive Biology 1991. 13: p. 73-95.

[21] Lowenstein, C., J. Dinerman, and S. Snyder, Nitric Oxide: A Physiologic Messenger Annual International Medical Journal, 1994. 120: p. 227-237.

[22] Boolell, M., et al., Sildenafil: an orally active type 5 cyclic GMP-specific phosphodiesterase inhibitor for the treatment of penile erectile dysfunction. International Journal of Impotency Research, 1996. 8(2): p. 47-52.

[23] Lue, T., Erectile dysfunction. North England Journal of Medicine, 2000. 342: p. 1802-1813.

[24] Kandeel, F., V. Koussa, and R. Swerdloff, Male sexual function and Its disorders: physiology, pathophysiology, clinical investigation, and treatment. Endocrine Review, 2001. 22(3): p. 342-388.

[25] Burnett, A., et al., Immunohistochemical description of nitric oxide synthase isoforms in human clitoris. The Journal of Urology, 1997. 158(1): p. 75-78.

[26] Park, K., et al., Sildenafil inhibits phosphodiesterase type 5 in human clitoral corpus cavernosum smooth muscle. Biochemical and Biophysical Research Communications, 1998. 249(3): p. 612-617.

[27] Crooks, R. and K. Baur, Our sexuality. 11th ed. 2011, Belmont: Thomson Wadsworth.

[28] Levin, R., The Physiology of Sexual Arousal in the Human Female: A Recreational and Procreational Synthesis. Archives of Sexual Behavior, 2002. 31(5): p. 405-411.

[29] Shafik, A., Vagino-levator reflex: Description of a reflex and its role in sexual performance. European Journal of Obstetrics and Gynecology and Reproductive Biology, 1995. 60: p. 161-164.

[30] Okami, P. and T. Shackelford, Human sex differences in sexual psychology and behavior. Annual Review of Sex Research, 2001. 12: p. 186-241.

[31] Salonia, A., et al., Women's sexual dysfunction: a pathophysiological review. BJU International, 2004. 93(8): p. $1156-1164$.

[32] Goldstein, I., et al., Oral sildenafil in the treatment of erectile dysfunction. New England Journal of Medicine, 1998. 338(20): p. 13971404.

[33] Food and Drug Administration, Approval for the application of viagra in erectile dysfunction. 1998, Author: Rockville.

[34] Croissant, J., The new sexual technobody: viagra in the hyperreal world. Sexualities, 2006. 9(3): p. 333-344.

[35] Meika, L., The rise of viagra: how the little blue pill changed sex in America. 2004, New York: New York University Press.

[36] McVary, K., et al., Sildenafil citrate improves erectile function and urinary symptoms in men with erectile dysfunction and lower urinary tract symptoms associated with benign prostatic hyperplasia: a randomized, double-blind trial. The Journal of Urology, 2007. 177(3): p. 1071-1077.

[37] Padma-Nathan, H., et al., Randomized, double-blind, placebo-controlled study of postoperative nightly sildenafil citrate for the prevention of erectile dysfunction after bilateral nerve-sparing radical prostatectomy. Int J Impot Res, 2008. 20(5): p. $479-486$.

[38] Loran, O., et al., Sildenafil citrate $100 \mathrm{mg}$ starting dose in men with erectile dysfunction in an international, double-blind, placebocontrolled study: effect on the sexual experience and reducing feelings of anxiety about the next intercourse attempt. The Journal of Sexual Medicine, 2009. 6(10): p. 2826-2835.

[39] Berman, J., et al., Safety and efficacy of sildenafil citrate for the treatment of female sexual arousal disorder: a double-blind, placebo controlled study. The Journal of Urology, 2003. 170(6, Part 1): p. 2333-2338. 
[40] Alexander, M., et al., Sildenafil in women with sexual arousal disorder following spinal cord injury. Spinal Cord, 2011. 49(2): p. 273279.

[41] Sipski, M., et al., Sildenafil effects on sexual and cardiovascular responses in women with spinal cord injury. Urology, 2000. 55(6): p. 812-815.

[42] Salerian, A., et al., Sildenafil for psychotropic-induced sexual dysfunction in 31 women and 61 men. Journal of Sex and Marital Therapy, 2000. 26(2): p. 133-140.

[43] Enck, P., F. Benedetti, and M. Schedlowski, New insights into the placebo and nocebo responses. Neuron, 2008. 59(2): p. $195-206$.

[44] Cavalcanti, A., et al., Effect of sildenafil on clitoral blood flow and sexual response in postmenopausal women with orgasmic dysfunction. International Journal of Gynecology \& Obstetrics, 2008. 102(2): p. 115-119.

[45] Basson, R., et al., Efficacy and safety of sildenafil citrate in women with sexual dysfunction associated with female sexual arousal disorder. Journal of Women's Health \& Gender-Based Medicine, 2002. 11(4): p. 367-377.

[46] Kaplan, S., et al., Safety and efficacy of sildenafil in postmenopausal women with sexual dysfunction. Urology, 1999. 53(3): p. 481486.

[47] Van Der Made, F., et al., Childhood sexual abuse, selective attention for sexual cues and the effects of testosterone with or without vardenafil on physiological sexual arousal in women with sexual dysfunction: a pilot study. The journal of sexual medicine, 2009. 6(2): p. 429-39.

[48] Chivers, M. and R. Rosen, Phosphodiesterase Type 5 Inhibitors and female sexual response: faulty protocols or paradigms? The journal of sexual medicine, 2010. 7(2pt2): p. 858-872.

[49] Kats, A., Sex when you are sick. 2009, Westport: Praeger.

[50] Masters, W. and V. Johnson, Human sexual response. 1966, Boston Little Brown.

[51] Basson, R., Female sexual response: the role of drugs in the management of sexual dysfunction. Obstet Gynecol 2001. 98(2): p. 350353.

[52] Basson, R., The Female Sexual Response: A Different Model. Journal of Sex \& Marital Therapy, 2000. $26(1)$ : p. 51 - 65.

[53] Chivers, M., et al., A sex difference in the specificity of sexual arousal. Psychological Science, 2004. 15(11): p. $736-744$.

[54] Chivers, M., et al., Agreement of self-reported and genital measures of sexual arousal in men and women: a meta-analysis. Archives of Sexual Behavior, 2010. 39(1): p. 5-56.

[55] Suschinsky, K., M. Lalumière, and M. Chivers, Sex differences in patterns of genital sexual arousal: measurement artifacts or true phenomena?. Archives of Sexual Behavior, 2009. 38(4): p. 559-573.

[56] Gerritsen, J., et al., The clitoral photoplethysmograph: a new way of assessing genital arousal in women. The journal of sexual medicine, 2009. 6(6): p. 1678-1687.

[57] Van Lunsen, R. and E. Laan, Genital vascular responsiveness and sexual feelings in midlife women: psychophysiologic, brain, and genital imaging studies. Menopause, 2004. 11(6, Part 2 of 2): p. 741-748.

[58] Karraker, A., J. DeLamater, and C. Schwartz, Sexual frequency decline from midlife to later ife. The Journals of Gerontology Series B: Psychological Sciences and Social Sciences, 2011.

[59] Carpenter, L., C. Nathanson, and Y. Kim, Physical women, emotional men: gender and sexual satisfaction in midlife. Archives of Sexual Behavior, 2009. 38(1): p. 87-107.

[60] Meston, C. and M. Worcel, The effects of Yohimbine plus L-arginine Glutamate on sexual arousal in postmenopausal women with sexual arousal disorder. Archives of Sexual Behavior, 2002. 31(4): p. 323-332.

[61] Laan, E., et al., The Enhancement of Vaginal Vasocongestion by Sildenafil in Healthy Premenopausal Women. Journal of Women's Health \& Gender-Based Medicine, 2002. 11(4): p. 357-365.

[62] Basson, R. and L. Brotto, Sexual psychophysiology and effects of sildenafil citrate in oestrogenised women with acquired genital arousal disorder and impaired orgasm: a randomised controlled trial. BJOG: An International Journal of Obstetrics \& Gynaecology, 2003. 110(11): p. 1014-1024.

[63] Brotto, L., R. Basson, and B. Gorzalka, Psychophysiological assessment in premenopausal sexual arousal disorder. Journal of Sexual Medicine 2004. 1(266-277).

[64] Taylor, J., et al., Differences in side-effect duration and related bother levels between phosphodiesterase type 5 inhibitors. BJU International, 2009. 103(10): p. 1392-1395.

[65] Rietema, H., et al., Sildenafil treatment in COPD does not affect stroke volume or exercise capacity. European Respiratory Journal, 2008. 31(4): p. 759-764.

[66] Goff, D., et al., A placebo-controlled study of sildenafil effects on cognition in schizophrenia. Psychopharmacology, 2009. 202(1): p. 411-417.

[67] Steers, W., Viagra: after one year. Urology, 1999. 54: p. 12.

[68] Tan, S., From genesis to genes. Ann Acad Med Singapore, 2003. 32: p. 710-716.

[69] Masters, W. and V. Johnson, Human sexual inadequacy. 1970, Boston: Little Brown.

[70] Kleinplatz, P., Beyond sexual mechanics and hydraulics: humanizing the discourse surrounding erectile dysfunction. Journal of Humanistic Psychology, 2004. 44(2): p. 215-242.

[71] Barker, M., Existential sex therapy. Sexual and Relationship Therapy 2011. 26(1): p. 33-47.

[72] Traish, A., et al., Development of human and rabbit vaginal smooth muscle cell cultures: effects of vasoactive agents on intracellular levels of cyclic nucleotides. Molecular Cell Biology Research Communications, 1999. 2(2): p. 131-137. 
[73] Goldstein, I. and J. Berman, Vasculogenic female sexual dysfunction: vaginal engorgement and clitoral erectile insufficiency syndromes. International Journal of Impototence Research, 1998. 10 (Suppl 2): p. S84-90.

[74] Hoyle, C., et al., Innervation of vasculature and microvasculature of the human vagina by NOS and neuropeptide-containing nerves. Journal of Anatomy, 1996. 188(Py 3): p. 633-644.

[75] Levin, R., Sexual desire and the deconstruction and reconstruction of the human female sexual response model of Masters and Johnson, in Energetics of the sexual system, W. Everaerd, E. Laan, and s. Both, Editors. 2000, Royal Netherlands Academy of Arts and Sciences: Amsterdam. p. 63.

[76] Abou-Saleh, M.T., R. Ghubash, and T.K. Daradkeh, Al Ain Community Psychiatric Survey. I. Prevalence and socio-demographic correlates. Social Psychiatry and Psychiatric Epidemiology, 2001. 36(1): p. 20-28. 